\title{
Prevalence and Factors Associated With Intimate Partner Violence Among Women With Abortion at Mulago Hospital, Kampala City, Uganda
}

JACKSON JOSEPH TABULEY ( $\square$ tabuleabu@yahoo.co.uk )

Liverpool Women's Hospital Department of Neonatal Care https://orcid.org/0000-0002-5026-7294

Nekemiah Katusiime

Mulago National Referral Hospital

Othman Kakaire

Makerere university college of health sciences

\section{Research}

Keywords: intimate partner violence, prevalence, factors associated, abortion, Uganda

Posted Date: January 15th, 2021

DOI: https://doi.org/10.21203/rs.3.rs-144244/v1

License: (c) (i) This work is licensed under a Creative Commons Attribution 4.0 International License.

Read Full License 


\section{Abstract}

Background: Intimate partner violence (IPV) is a global health problem causing ill health among women especially of reproductive age. Its global prevalence is estimated to be $30-71 \%$. The prevalence is higher among African and Asian populations compared to American and European populations. In Uganda, the prevalence of IPV among women with abortion was $56.4 \%$ in 2005 . Since then, the Domestic Violence Act was enacted in 2010; sexual and gender based violence desks initiated in hospitals and a number of agencies working to prevent violence against women have sprung up. The objective of this study was to determine the current prevalence and factors associated with IPV among women with abortion at Mulago National Referral Hospital in Kampala city.

Methods: A hospital based cross-sectional study was conducted over 4 months on 480 women. Data were collected using an interviewer-administered questionnaire and analyzed using STATA 13.0. Those variables with a p-value $\leq 0.05$ were considered statistically significant at multi-variate analysis.

Results: The prevalence of IPV among women with abortion was 71.3\%. The factors that were significantly associated with intimate partner violence were: being divorced/widowed/separated (aOR 8.7, $\mathrm{Cl} 1.1997-38.268$, and p-value $=0.004)$, being never married (aOR 5.5, $\mathrm{Cl} 2.700-11.138$, and p-value $<0.001$ ), number of children (aOR 1.2, $\mathrm{Cl} 1.053-1.411$ and $p$-value $=0.008)$ and witnessing abuse as an adult (aOR 6.1, $\mathrm{Cl}$ 2.678-13.727, and p-value <0.001).

Conclusion: This study has shown that the prevalence of IPV among women with abortion is still high despite interventions. More concerted effort needs to be directed toward improving contraceptive services, marriage and family support systems and community awareness on the effects of IPV on women and society.

\section{Plain English Summary}

Intimate partner violence (IPV) is a common problem in Uganda contributing immensely to ill health, especially among women in reproductive age. In this study we set out to determine how wide spread IPV is and find factors leading to its perpetration among women with abortion seeking care at gynaecology department of Mulago national referral hospital in Kampala, Uganda.

The respondents were interviewed using a face-to-face interviewer administered questionnaire, which had preset questions about number of children, history of witnessing abuse, marital status, history abortion among other aspects including demographic and social characteristics.

Out of the 480 participants: 342 had experienced IPV; 308 of these experienced controlling behaviour; 227economic violence; 189 suffered sexual violence; 187 emotional violence; and 150 had survived physical violence. More than one response was allowed for the different types of IPV. 
The most common factors associated with IPV were: increasing number of children; witnessing violence as an adult; being divorced, widowed or separated; and being never married. The least common factors associated with IPV were: witnessing violence as a child; HIV status of partner; and the participants. It is therefore recommended that Health service providers should improve screening for IPV, access to contraceptive and family planning, services.

In conclusion: there is still high prevalence of IPV among women with abortion requiring concerted efforts of all stake holders. The types of IPV perpetrated and associated factors identified will help inform policy and future research strategies into mechanisms to eradicate IPV.

\section{Background}

The term 'domestic violence' is used in many countries to refer to intimate partner violence (IPV) but the term can also encompass child or elder abuse, or abuse by any member of a household (WHO, 2012). IPV among women refers to any behaviour within an intimate relationship that causes physical (slapping, hitting, kicking and beating), psychological (insults, belittling, constant humiliation, intimidation, threats of harm and threats to take away children), sexual harm (forms of sexual coercion) or controlling behaviours (isolating a person from family and friends; stalking; restricting access to financial resources, employment, education or medical care) to the woman in the relationship (WHO, 2012).

This health problem, contributes to serious gynecologic consequences such as unintended/unwanted pregnancies, pregnancy complications such as abortions, and sexually transmitted infections including HIV (WHO, 2013). It also leads to long lasting physical impairment, emotional trauma, chronic health problems, and even death (American College of Obstetricians and Gynecologists, 2012). It has affected millions of women irrespective of age, race, religion, sexual orientation, economic status, ethnicity or educational background (Aston \& Bewley, 2009)

Women in violent relationships are unlikely to use contraceptives consistently and end up with unintended pregnancies. Evidence shows that majority of these unplanned pregnancies end up in unsafe induced abortions, which lead to multiple complications (García-Moreno, Jansen, Ellsberg, Heise, \& Watts, 2005).

Globally, the prevalence of IPV among women of reproductive age ranges from $30-71 \%$, with the highest figures recorded among African and Asian countries (WHO, 2013). The main forms of IPV are physical (13-61\%), sexual (6-59\%) and psychological/emotional (20-75\%) (Garcia-Moreno, Heise, Jansen, Ellsberg, \& Watts, 2005). In Ethiopia, the prevalence of IPV is 54\% (Garcia-Moreno et al., 2005). A study done on male college students in Ethiopia estimated that $15.8 \%$ and $16.9 \%$ of them had physically and sexually abused their female partners respectively (Philpart, Goshu, Gelaye, Williams, \& Berhane, 2009).

The prevalence of IPV among women with abortion in Uganda was estimated to be $57 \%$ in the year 2000 (D Kaye, Mirembe, \& Bantebya, 2001). Five years later, the prevalence reduced by $0.6 \%$ (D. K. Kaye, Mirembe, Bantebya, Johansson, \& Ekstrom, 2006). 
Since then interventions such as the initiation of sexual and gender based violence (SGBV) desks in the departments of Obstetrics and Gynaecology and a number of agencies for instance UNICEF, FIDA, UWONET and Raising Voices have sprung up. In 2010, the Domestic Violence Act was also enacted.

It is not known to what extend these interventions have impacted on the prevalence and factors associated with IPV among women with abortion in Uganda. Therefore, this study was conducted to determine the current prevalence and factors associated with IPV among hospitalized women presenting with abortion at Mulago National Referral Hospital (MNRH). The information obtained from the results of this study will form a basis for guiding policy and strengthening intervention strategies.

\section{Methods}

\section{Study setting}

A cross-sectional study was conducted in the emergency gynaecology ward in the department of Obstetrics and Gynaecology at Mulago National Referral Hospital from November 2016 to February 2017.

On this ward, apart from the management of women with abortion, other services include management of other gynaecological emergencies such as ectopic pregnancies; HIV testing and counseling, and the provision of post exposure prophylaxis. This unit also has outpatient clinics for follow-up of patients, as well as a section for the screening, treating and counseling of survivors of SGBV.

Women with abortions are attended to at the emergency gynaecology ward where initial management is done. If further inpatient care is required, they are then transferred to general gynaecology ward.

We included women in reproductive age (15 to 49 years) who had been diagnosed with abortion (irrespective of the type of abortion) at the emergency gynaecology ward of MNRH and consented to participate in the study. Those between 15 and 18 years were considered emancipated minors, while women too sick to give consent (comatose) were excluded.

\section{Sample Size}

Using the Kish \& Leslie (1965) formula, at 10\% non-response for prevalence and using Open-Epi with Fleiss formula at $5 \%$ non-response for factors associated with IPV, the sample size was adjusted to $\mathbf{4 8 0}$ participants.

\section{Sampling procedure}

Consecutive sampling was used to obtain study participants considering an average of 5-10 abortion patients admitted every day. Eligible participants were asked to sign or put a thump print on the informed consent form in order to be recruited into the study.

\section{Study procedure}


A total of 480 women who presented at the emergency gynaecology ward and had been diagnosed with abortion, either clinically and/or by ultra sound scan were recruited. After undergoing treatment and were clinically stable, they gave their written- informed consent, after which an interviewer-administered questionnaire was filled in by the by principal investigator or research assistant (Appendix 1 ). To ensure quality control, the research assistants (two senior midwives) were trained on ethical issues and data collection using the modified UDHS 2011 questionnaire.

Data management and analysis: The data was collected and cross-checked daily to ensure that the questionnaires where appropriately filled. The data was entered into Epi-data version 3.1 and analyzed using STATA version 13.0. The entered questionnaires were then stored in a safe drawer under lock and key only accessible to the principal investigator.

The prevalence of IPV among women with abortion was calculated as a proportion of the study participants. The numerator was the number of women with abortion who experienced IPV of any kind and the denominator was the total number of women enrolled into the study. The different types of IPV were presented as proportions of the women with abortion. These were then expressed as percentages.

To determine the factors associated with IPV, a series of bivariate and multi-variate logistic regression analysis were performed and odds ratios with corresponding $95 \%$ confidence intervals were estimated. During bivariate analysis, factors with $p$-value of $\leq 0.2$ were considered for multivariate analysis. Those factors with $p$-value $\leq 0.05$ at multivariate analysis were considered statistically significant.

\section{Results}

\section{Socio-demographics and behavioral characteristics of the participants}

Our sample consisted of 480 women (Table 1). Over half were urban dwellers $323(67.3 \%)$, aged less than 24 years of age 131 (48.2\%), of Bantu tribe $376(78.3 \%)$ and married 338 (70.4\%). Majority of the women had attained a secondary level of education 277 (57.7\%). Most women 299 (62.3\%) did not know the HIV status of their partners and majority did not drink nor use recreational drugs. Of those who witnessed abuse, 368 (76.7\%) had witnessed abuse as a child while 408 (85\%) witnessed abuse as an adult (Table 2).

\section{Prevalence Of Intimate Partner Violence Against Women}

The prevalence of IPV among women with abortion was 342 (71.3\%) (Fig. 1). 74 (15.4\%) suffered only one type of IPV, while $86(25.2 \%)$ suffered all 5 types (Table 3 ). Controlling behaviour and economic IPV contributed most to intimate partner violence (Table 4). 101 (29.5) \% of the women who suffered IPV had induced the current abortion. $73(70.2 \%)$ of the women who had induced previous abortions suffered IPV. 


\section{The Factors Independently Associated With Ipv}

Using logistic regression models, compared to women who were married/living together with their intimate partners, those that were divorced/widowed/separated were more likely to suffer IPV (OR8.7,95\% $\mathrm{Cl} 1.997-38.268$ ) as well as those who were never married (OR5.5, 95\% $\mathrm{Cl} 2.700-11.143)$. Having more than one child increased the risk of suffering IPV $(\mathrm{OR} 1.2,95 \% \mathrm{Cl} 1.053-1.411)$ as well as witnessing abuse as an adult (OR 6.1, 95\% Cl 2.678-13.727). 
Table 1

Demographic characteristics of the participants $(n=480)$

\begin{tabular}{|c|c|c|}
\hline Characteristic & Frequency (n) & Percentage (\%) \\
\hline \multicolumn{3}{|l|}{ Age } \\
\hline $15-19$ & 69 & 14.4 \\
\hline $20-24$ & 162 & 33.8 \\
\hline $25-29$ & 137 & 28.5 \\
\hline $30-34$ & 63 & 13.1 \\
\hline $35-39$ & 41 & 8.5 \\
\hline$>40$ & 8 & 1.7 \\
\hline \multicolumn{3}{|l|}{ Religion } \\
\hline Catholic & 157 & 32.7 \\
\hline Protestant & 105 & 21.9 \\
\hline Muslim & 118 & 24.6 \\
\hline Pentecostal & 58 & 12.1 \\
\hline SDA & 15 & 3.1 \\
\hline Other & 27 & 5.6 \\
\hline \multicolumn{3}{|l|}{ Ethnicity } \\
\hline Bantu & 376 & 78.3 \\
\hline Non-bantu & 104 & 21.7 \\
\hline \multicolumn{3}{|l|}{ Residence } \\
\hline Urban & 323 & 67.3 \\
\hline Rural & 157 & 32.7 \\
\hline \multicolumn{3}{|l|}{ Marital status } \\
\hline Never married & 98 & 20.4 \\
\hline Married/living together & 338 & 70.4 \\
\hline Divorced/widowed/separated & 44 & 9.2 \\
\hline \multicolumn{3}{|l|}{ Type of marriage* } \\
\hline Monogamous & 272 & 80.5 \\
\hline
\end{tabular}




\begin{tabular}{|lll|}
\hline Characteristic & Frequency (n) & Percentage (\%) \\
\hline Polygamous & 66 & 19.5 \\
\hline Employment & & \\
\hline Employment for cash & 152 & 31.7 \\
\hline Employment not for cash & 195 & 40.6 \\
\hline Unemployed & 133 & 27.7 \\
\hline Level of education & & \\
\hline S primary education & 203 & 42.3 \\
\hline$\geq$ secondary & 277 & 57.7 \\
\hline * Only 338 women participants were married & \\
\hline
\end{tabular}


Table 2

Behavioral characteristics of Participants $(n=480)$

\begin{tabular}{|c|c|c|}
\hline & Frequency (n) & Percentage (\%) \\
\hline \multicolumn{3}{|c|}{ Reported HIV status of participant } \\
\hline Positive & 31 & 6.5 \\
\hline Negative & 223 & 46.5 \\
\hline Unknown & 226 & 47.1 \\
\hline \multicolumn{3}{|c|}{ Reported HIV status of intimate partner } \\
\hline Positive & 20 & 4.2 \\
\hline Negative & 161 & 33.5 \\
\hline Unknown & 299 & 62.3 \\
\hline \multicolumn{3}{|c|}{ Alcohol consumption of participant } \\
\hline Does not drink & 447 & 93.1 \\
\hline Drinks alcohol & 33 & 6.9 \\
\hline \multicolumn{3}{|c|}{ Alcohol consumption of intimate partner } \\
\hline Does not drink & 354 & 73.7 \\
\hline Drinks alcohol & 126 & 26.3 \\
\hline \multicolumn{3}{|c|}{ Recreational drug use of participant } \\
\hline Does not take drugs & 478 & 99.6 \\
\hline Takes drugs & 2 & 0.4 \\
\hline \multicolumn{3}{|c|}{ Recreational drug use of intimate partner } \\
\hline Does not take drugs & 474 & 98.7 \\
\hline Takes drugs & 6 & 1.3 \\
\hline \multicolumn{3}{|c|}{ Witnessed abuse as child } \\
\hline Yes & 368 & 76.7 \\
\hline No & 112 & 23.3 \\
\hline \multicolumn{3}{|c|}{ Witnessed abuse as adult } \\
\hline Yes & 408 & 85.0 \\
\hline No & 72 & 15.0 \\
\hline
\end{tabular}


Table 3

IPV and types of abortion $(\mathrm{n}=480)$

\begin{tabular}{|c|c|c|c|}
\hline & No IPV (\%) & IPV (\%) & p-value/Chi2 \\
\hline \multicolumn{4}{|c|}{ Type of current abortion } \\
\hline Spontaneous & $130(94.2)$ & $241(70.5)$ & $<0.001 / 31.559$ \\
\hline Induced & $8(5.8)$ & $101(29.5)$ & \\
\hline \multicolumn{4}{|c|}{ Type of previous abortion* } \\
\hline Spontaneous & $31(86.1)$ & $31(29.8)$ & $0.060 / 3.548$ \\
\hline induced & $5(13.9)$ & $73(70.2)$ & \\
\hline
\end{tabular}

Table 4

Proportions of the different types of IPV experienced by participants $(n=342)$

\begin{tabular}{|lll|}
\hline Type of IPV suffered & Frequency (n) & Percentage (\%) \\
\hline Emotional & 187 & 54.7 \\
\hline Physical & 150 & 43.9 \\
\hline Sexual & 189 & 55.3 \\
\hline Economic & 227 & 66.4 \\
\hline Controlling & 308 & 90.1 \\
\hline *More than one response was allowed \\
\hline
\end{tabular}


Table 3

Factors independently associated with IPV at multivariate analysis

\begin{tabular}{|c|c|c|c|}
\hline Variable & $a O R$ & $95 \% \mathrm{Cl}$ & $p$-value \\
\hline \multicolumn{4}{|l|}{ Religion } \\
\hline \multicolumn{4}{|l|}{ Catholic } \\
\hline Protestant & 1.6 & $0.804-2.997$ & 0.190 \\
\hline Muslim & 1.1 & $0.577-1.931$ & 0.860 \\
\hline Pentecostal & 1.1 & $0.517-2.407$ & 0.780 \\
\hline SDA & 1.4 & $0.415-4.967$ & 0.568 \\
\hline Others & 0.8 & $0.286-2.200$ & 0.657 \\
\hline \multicolumn{4}{|l|}{ Ethnicity } \\
\hline Bantu & 1 & & \\
\hline Non-bantu & 0.6 & $0.374-1.087$ & 0.098 \\
\hline \multicolumn{4}{|l|}{ Residence } \\
\hline Urban & 1 & & \\
\hline Rural & 1.4 & $0.715-2.635$ & 0.342 \\
\hline \multicolumn{4}{|l|}{ Marital status } \\
\hline Married/living together & 1 & & \\
\hline Divorced/widowed/separated & 8.7 & $1.997-38.268$ & $\star 0.004$ \\
\hline Never married & 5.5 & $2.700-11.138$ & $* 0.000$ \\
\hline Number of children & 1.2 & $1.053-1.411$ & $* 0.008$ \\
\hline \multicolumn{4}{|c|}{ Reported HIV status of participant } \\
\hline \multicolumn{4}{|l|}{ Positive } \\
\hline Negative & 0.9 & $0.263-2.908$ & 0.827 \\
\hline Unknown & 0.8 & $0.246-2.732$ & 0.747 \\
\hline \multicolumn{4}{|c|}{ Reported HIV status of intimate partner } \\
\hline \multicolumn{4}{|l|}{ Positive } \\
\hline Negative & 0.4 & $0.078-1.735$ & 0.206 \\
\hline Unknown & 0.7 & $0.158-2.927$ & 0.605 \\
\hline
\end{tabular}




\begin{tabular}{|llll|}
\hline Variable & aOR & $95 \% \mathrm{Cl}$ & p-value \\
\hline Alcohol consumption of intimate partner & & & \\
\hline Does not drink & & & \\
\hline Drinks alcohol & 1.7 & $0.969-3.060$ & 0.064 \\
Witnessed abuse as child & & & \\
\hline No & & & \\
Yes & 0.7 & $0.318-1.394$ & 0.280 \\
\hline Witnessed abuse as adult & & & \\
\hline No & & & \\
\hline Yes & 6.1 & $2.678-13.727$ & $* 0.000$ \\
\hline *Significant & & & \\
\hline
\end{tabular}

\section{Discussion}

The prevalence of IPV among women found in this study was $14.9 \%$ higher than that reported in a similar study in 2005 in the same setting (D. K. Kaye et al., 2006). In the general population by 2012, the prevalence of IPV among the women of reproductive age was 59.7\% (UBOS, 2012). This is much lower than reported in this study by $>10 \%$.

The higher prevalence in this study could be explained by the number of young women less than 30 years of age recruited in this study. This age group is more likely to experience IPV due to the social pressures and stress associated with high unemployment rates in this age group. This correlates with the findings in the general population which shows that most young people under the age of 30 years are unemployed (UBOS, 2016).

An alternative explanation to this could be improved reporting of IPV in the study site resulting from the interventions that have taken place over time. The availability of these interventions could have empowered more women to report IPV.

Another study done in Mbeya, Tanzania found a lower prevalence of IPV among women with abortion (56\%) (Stöckl, Filippi, Watts, \& Mbwambo, 2012). This was attributed to under reporting of IPV due to cultural beliefs in Mbeya and violence against women being considered a norm (Stöckl et al., 2012).

In Bangladesh, three quarters of women in the general population experienced IPV similar to the findings of this study (Silverman, Gupta, Decker, Kapur, \& Raj, 2007). The similarity in the findings of these two studies could be because IPV prevention services in the two countries are inadequate. For example, these services may only be helping to identify the victims and offering psychological support. It could also be 
that services are only helping to improve reporting of IPV but no or little attempt is made to target the perpetrators as it is known that reporting could be enhanced by services that empower women.

In a WHO multi-country study, the prevalence of IPV among women of reproductive age in the general population varied from low to high income countries; ranging from $15 \%$ in high income to $71 \%$ in low income countries (Garcia-Moreno et al., 2005). This difference in the prevalence of IPV between low and high income countries could be because of the difference in the quality of preventive services for violence against women.

Most of the study participants had suffered more than one type of IPV with more than a quarter having experienced only one type of IPV or all 5 types. The trend in the experience of the different types of IPV could be an indication that most men have resorted to other means of violence like controlling behaviour, economic deprivation and emotional violence because these types of violence are difficult to quantify or even verify in courts of law. In the study by D. Kaye et al., physical violence was the most common type of violence among women with abortion (D. K. Kaye et al., 2006). This shift could have arisen as a result of the fear brought about by the Domestic Violence Act 2010 which stipulates criminal and civil penalties for violence against women.

\section{Ipv And Abortion}

This study showed that more than one third of the study participants who suffered IPV had induced abortions. This is consistent with the findings by D. Kaye et al that showed women with induced abortion to be more likely to report IPV (D. K. Kaye et al., 2006).

A study in Nigeria also found that women exposed to IPV exhibited a higher likelihood of having a history of miscarriages and induced abortions (Okenwa, Lawoko, \& Jansson, 2011).

Interestingly in this study, nearly three quarters of the women with repeat abortion who reported IPV had induced abortion. In China, a study on domestic violence against women seeking induced abortion found that those who suffered IPV had a higher likelihood of reporting repeat abortions (Wu, Guo, \& Qu, 2005).

\section{Factors Associated With Ipv}

In agreement with the UDHS 2011 report, this study showed that women who were divorced, separated, or widowed were more likely to report experiencing violence compared to women who are married/living together with their intimate partners (UBOS, 2012). However, those findings contradict some studies which showed that women who are divorced or separated experienced the least IPV compared to those who are married/living together (D. K. Kaye et al., 2006). One plausible reason for the difference is the presence of agencies empowering women who are divorced/widowed/separated and supporting their cause. This could have led to increased reporting of IPV. 
However, results of this study agreed with those of D. Kaye et al which found that women who were never married to their partners reported a higher prevalence of IPV compared to those who are married (D. K. Kaye et al., 2006). An explanation for this finding could be lack of commitment and emotional bonding in such a relationship.

It was also found that for every additional child a woman had, she was more likely to suffer IPV (Table 4). This finding is similar to that of D. Kaye et al in which violence among women with abortion increased with parity (Dan Kaye, 2001). A multi-country study similarly showed that a progressive increase in IPV was linked with increasing number of children (Kishor \& Johnson, 2004). This was probably due to a rise in the socio-economic burden thus escalating stress in the relationship.

Whereas D. Kaye et al found that post-abortion women who had witnessed abuse as a child are more likely to experience IPV (Dan Kaye, 2001), this study in contrast linked it to witnessing abuse in adulthood. This is also contrasting to another study done in western Kenya which found that pregnant survivors of IPV had witnessed maternal abuse in their childhood (Makayoto, Omolo, Kamweya, Harder, \& Mutai, 2013). The reason is probably that the individual grows up in settings where IPV is common and are therefore exposed to the same cultural environment as their parents or peers experiencing IPV (Rani, Bonu, \& Diop-Sidibe, 2004). For witnessing violence as adults, the reason could be the increasing violence in Kampala between the police and civilians on streets accompanied by economic stress, as well as media showing violence in homes on television.

Other documented risk factors for IPV such as younger age (20-29 years), type of marriage, length of marriage, level of education and unemployment and history of previous abortion, were not found to be statistically significant.

\section{Study Limitations}

Since this study was a cross-sectional, it was difficult to determine causality. For example it was difficult to determine if the risk factor (e.g. being divorced/widowed/separated) was present prior to the IPV or whether the factor might have been an outcome of the IPV.

Another limitation to this study was selection bias arising from studying only women who presented at the emergency gynaecological ward. This excluded those who died before reaching the hospital or before receiving any care; those who never sought care at all or those who sought care in other health units. It was therefore difficult to determine the effect of these circumstances on the results of this study.

A short time for the study and limited financial resources could not provide for a bigger sample size. This also restricted us to single Centre-study instead of a multi-Centre which would have made the study results more generalizable.

\section{Conclusion And Recommendations}


This study has shown that the prevalence of IPV among women with abortion is still high despite the available interventions. The factors independently associated with IPV were an increasing number of children, witnessing abuse as an adult and being divorced/widowed/separated and being never married.

It is therefore recommended that there should be commitment from the Ministry of Gender, Labour and Social Development and the Judiciary to prevent and punish perpetrators of IPV. This should include development of evaluation and monitoring programs aimed at the primary prevention of IPV. Health service providers should improve screening for IPV, access to family planning and contraceptive services and information. Further research studies may help to understand the relationship between IPV and abortion; the help-seeking behaviour of women survivors of IPV as well as determining the factors for IPV among perpetrators.

\section{Acronyms And Abbreviations}
AIDS
Acquired Immune Deficiency Syndrome

ANC

Antenatal care

CEDOVIP

Centre for Domestic Violence Prevention

CEMACH

Confidential Enquiry into Maternal and Child Health

DVA

Domestic Violence Act

FIDA

Uganda Association of Women Lawyers

HIV

Human Immune Deficiency Virus

IPV

Intimate Partner Violence

MNRH

Mulago National Referral Hospital

$\mathrm{MoH}$

Ministry of Health

MakCHS

Makerere University College of Health Sciences

PI

Principal Investigator

PTSD

Post Traumatic Stress Disorder

RA

Research Assistant

SDGs

Sustainable Development Goals

SGBV

Sexual and Gender Based Violence 
SHO Senior House Officer

SOMREC School Of Medicine Research and Ethics Committee

STI Sexually Transmitted Infections

UDHS Uganda Demographic Health Survey

UNICEF United Nations Children's Fund

UWONET Uganda Women's network

WHO World Health Organization

\section{Declarations}

\section{Competing interests}

The author(s) declare that they have no competing interests.

2. Ethical approval and consent to participate: Permission to conduct the study was sought from School of Medicine Research and Ethics Committee and Uganda National Council of Science and Technology. Ethical approvals were obtained from the Department of Obstetrics and Gynaecology and Mulago National Referral Hospital. For purposes of confidentiality, a unique number and not the study participants' names were assigned by the PI or RA on the questionnaire and file for every participant. Disclosure of induced abortion, the method used and experience of IPV was kept confidential. It was ensured that the collection of data did not interfere with the emergency and routine care given to the patients

3. Availability of data and material: All the data and material used for this study available and can be shared with the publisher

\section{Authors' contributions}

JJT participated in the conception, proposal development, data collection, statistical analysis, interpretation of results and manuscript writing. NK participated in interpretation and editing of the manuscript, while, OK participated in conception, proposal development, statistical analysis and manuscript writing. All authors read and approved the final manuscript.

\section{Acknowledgments}

We are grateful to the research assistants (Sr. Madina Namufumba and Sr. Elizabeth Orodriyo) for assist in the data collection; Dr. Dickens Aturwanaho, Dr. Asiki Gershim and Dr. Clare Lubulwa who assisted with data analysis; and all the participants for their sacrifices during the interviews. 


\section{References}

Aston, Gillian, \& Bewley, Susan. (2009). Abortion and domestic violence. The Obstetrician \& Gynaecologist, 11(3), 163-168.

Garcia-Moreno, Claudia, Heise, Lori, Jansen, Henrica AFM, Ellsberg, Mary, \& Watts, Charlotte. (2005). Violence against women. Science, 310(5752), 1282-1283.

García-Moreno, Claudia, Jansen, Henrica AFM, Ellsberg, Mary, Heise, Lori, \& Watts, Charlotte. (2005). WHO multi-country study on women's health and domestic violence against women: initial results on prevalence, health outcomes and women's responses: World Health Organization.

Kaye, D, Mirembe, F, \& Bantebya, G. (2001). Risk factors, nature and severity of domestic violence among women attending antenatal clinic in Mulago Hospital, Kampala, Uganda. The Central African journal of medicine, 48(5-6), 64-68.

Kaye, Dan. (2001). Domestic violence among women seeking post-abortion care. International Journal of Gynecology \& Obstetrics, 75(3), 323-325.

Kaye, Dan K, Mirembe, Florence M, Bantebya, Grace, Johansson, Annika, \& Ekstrom, Anna Mia. (2006). Domestic violence as risk factor for unwanted pregnancy and induced abortion in Mulago Hospital, Kampala, Uganda. Tropical Medicine \& International Health, 11(1), 90-101.

Kishor, Sunita, \& Johnson, Kiersten. (2004). Profiling domestic violence: A multi-country study.

Makayoto, Lyndah A, Omolo, Jared, Kamweya, Abel M, Harder, Valarie S, \& Mutai, Joseph. (2013). Prevalence and associated factors of intimate partner violence among pregnant women attending Kisumu District Hospital, Kenya. Maternal and child health journal, 17(3), 441-447.

Obstetricians, American College of, Gynecologists, Obstetricians, American College of, \& Gynecologists. (2012). Intimate partner violence. Committee opinion no. 518. Obstet Gynecol, 119(2), 412-417.

Organization, World Health. (2012). Understanding and addressing violence against women: Intimate partner violence.

Organization, World Health. (2013). Violence against women: A "global health problem of epidemic proportions"-New clinical and policy guidelines launched to guide health sector response. News release, June, 20.

Philpart, Marc, Goshu, Miruts, Gelaye, Bizu, Williams, Michelle A, \& Berhane, Yemane. (2009). Prevalence and risk factors of gender-based violence committed by male college students in Awassa, Ethiopia. Violence and Victims, 24(1), 122-136. 
Rani, Manju, Bonu, Sekhar, \& Diop-Sidibe, Nafissatou. (2004). An empirical investigation of attitudes towards wife-beating among men and women in seven sub-Saharan African countries. African journal of reproductive health, 116-136.

Silverman, Jay G, Gupta, Jhumka, Decker, Michele R, Kapur, Nitin, \& Raj, Anita. (2007). Intimate partner violence and unwanted pregnancy, miscarriage, induced abortion, and stillbirth among a national sample of Bangladeshi women. BJOG: An International Journal of Obstetrics \& Gynaecology, 114(10), 12461252.

Stöckl, Heidi, Filippi, Veronique, Watts, Charlotte, \& Mbwambo, Jessie KK. (2012). Induced abortion, pregnancy loss and intimate partner violence in Tanzania: a population based study. BMC pregnancy and childbirth, 12(1), 12.

UBOS, ICF. (2012). Uganda demographic and health survey 2011. Kampala and Claverton: Uganda Bureau of Statistics and ICF International Inc.

UBOS, ICF. (2016). Uganda demographic and health survey 2016. Kampala and Claverton: Uganda Bureau of Statistics and ICF International Inc.

Wu, Jiuling, Guo, Sufang, \& Qu, Chuanyan. (2005). Domestic violence against women seeking induced abortion in China. Contraception, 72(2), 117-121.

\section{Figures}




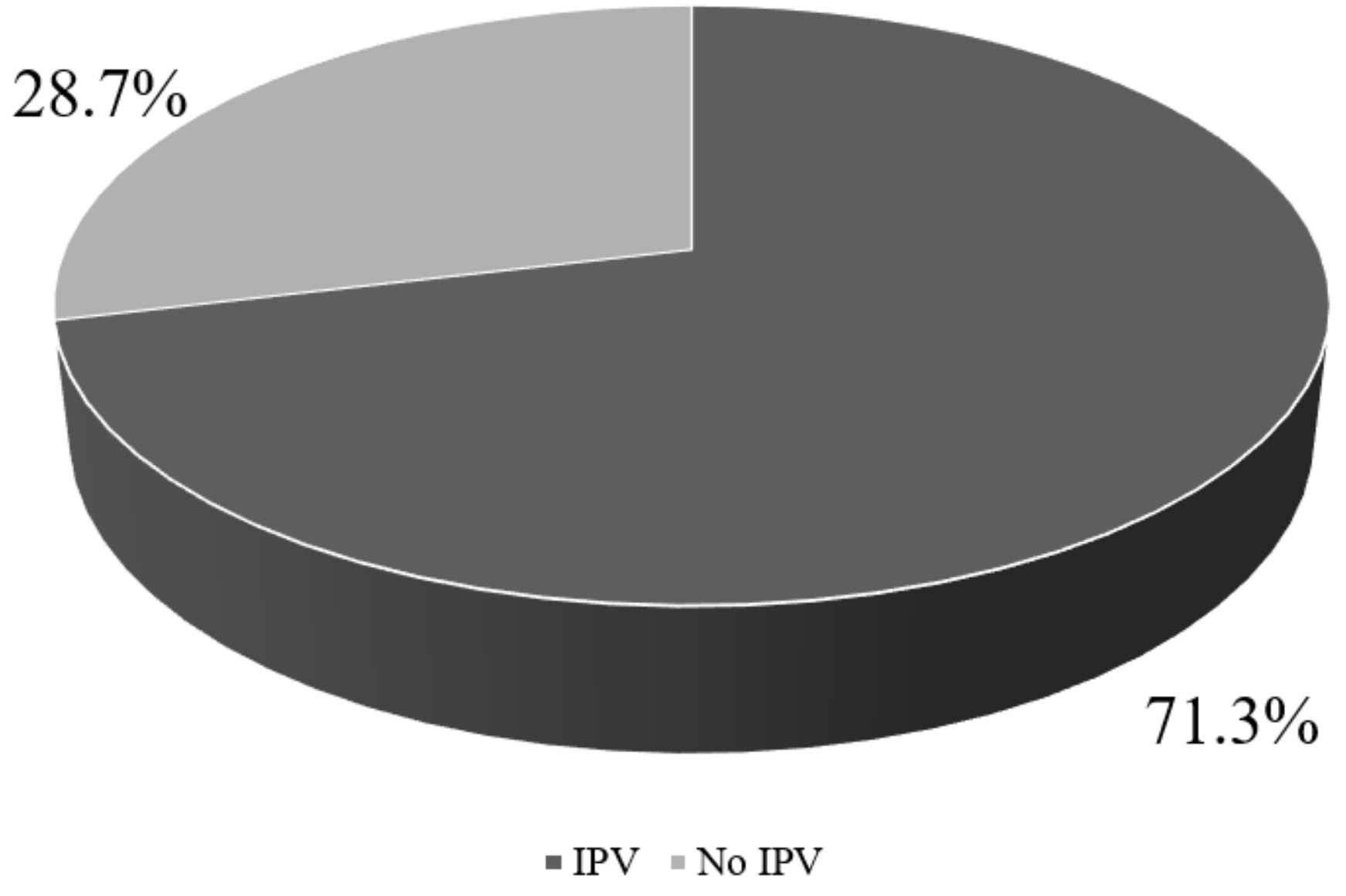

Figure 1

Prevalence of intimate partner violence $(n=480)$ 